\title{
The natural history of acute painful neuropathy in diabetes mellitus
}

\author{
AG ARCHER, PJ WATKINS, PK THOMAS, AK SHARMA, J PAYAN \\ From the Diabetic Department and Department of Neurology, King's College Hospital, and Department of \\ Neurological Science, Royal Free Hospital School of Medicine, London, UK
}

SUMMARY Observations have been made on nine cases of painful diabetic neuropathy of acute onset. All cases were male and all were associated with and preceded by precipitous and severe weight loss. The pain was of a continuous burning quality and experienced mainly in the legs, especially distally. Contact discomfort of the skin was often a troublesome feature, but sensory loss was mild or absent, and reflex loss or depression not invariable. There were no accompanying motor signs. Depression and impotence were constant features. The weight loss responded to adequate control of the diabetes with insulin and was followed by improvement in the neuropathy. The severe manifestations subsided in all cases within 10 months, and in most cases within 6 months, and later resolved completely in all except one. No recurrences were observed after follow-up periods of up to 6 years. Abnormalities of nerve conduction were mild or even lacking. Sural nerve biopsies from three cases taken in the acute stage showed evidence of active degeneration of myelinated nerve fibres of all diameters and also degeneration of unmyelinated axons. There was a mild degree of demyelination. It is concluded that acute painful diabetic neuropathy is a distinct syndrome, occurring in insulin or noninsulin dependent patients of any duration, and unrelated to other diabetic complications. It is separable from other types of painful diabetic sensory polyneuropathy that have been described.

When diabetic neuropathy was first adequately defined during the latter part of the last century, it was recognised that it could be manifested either by patchy and predominantly motor involvement or as a more diffuse and mainly sensory disorder. ${ }^{1}$ The latter was subdivided into a painful or "hyperalgesic" form and an ataxic or "pseudotabetic" variety, ${ }^{2}$ foreshadowing the separation into small and large fibre types advocated in recent years by Brown et al. ${ }^{3}$ The features of the pain in the hyperalgesic form were documented by $\mathrm{Pavy}^{4}$ who noted that it was of burning and unremitting quality. $\mathrm{He}$ emphasised the characteristic exaggeration at night. It was also commented that affected individuals often complained of a sensation in the feet when walking that was likened to treading barefoot on pebbles. Focal and multifocal neuropathies such as isolated lesions of cranial or limb nerves, or diabetic amyotrophy, may also be painful.

Address for reprint requests: Dr AG Archer, Diabetic Department, King's College Hospital, Denmark Hill, London SE5 9RS, UK.

Received 15 December 1982. Accepted 17 January 1983.
So far there have been very few observations on the natural history, neurophysiology and histopathology of the painful symmetrical neuropathy, and the long term outlook for these patients has not been adequately defined. The purpose of this study is to describe the events during and for several years after the onset of acute painful neuropathy in a group of nine diabetic patients who were exceptionally severely affected, together with the nerve biopsy findings in three. These cases have in recent years been best described by Ellenberg ${ }^{5}$ as "diabetic neuropathic cachexia".

\section{Patients and methods}

Patients (table 1)

Nine diabetics referred because of intolerable unrelenting pain in the feet and legs have been assessed. In all, the magnitude of the pain was sufficient to disrupt their lives completely. All were male and their ages ranged from 32 to 61 years and there was one adolescent aged 13 years. Five were insulin dependent, while the remainder were not insulin dependent, although these were treated with insulin because of their neuropathy. A full assessment was made at the time of onset of the acute symptoms and another at 
Table 1 Clinical data on 9 cases of painful diabetic neuropathy

\begin{tabular}{|c|c|c|c|c|c|c|c|c|c|c|c|}
\hline \multirow[t]{2}{*}{ Case } & \multicolumn{2}{|c|}{ Age at onset (yr) } & \multicolumn{2}{|l|}{ Treatment } & \multicolumn{2}{|c|}{$\begin{array}{l}\text { Average blood sugar } \\
\left.\text { (mmols } l^{-1}\right)\end{array}$} & \multicolumn{2}{|c|}{$\begin{array}{l}\text { Maximum } \\
\text { weight loss }\end{array}$} & \multicolumn{3}{|c|}{ Duration of symptoms (months) } \\
\hline & Diabetes & $\begin{array}{l}\text { Painful } \\
\text { neuropathy }\end{array}$ & Prior $\mathrm{KCH}$ & At $K C H$ & Prior $\mathrm{KCH}$ & At $\mathrm{KCH}$ & $k g$ & $\%$ & Moderate & Severe & Residual \\
\hline $\begin{array}{l}1 \\
2 \\
3 \\
4 \\
5 \\
6 \\
7 \\
8 \\
9\end{array}$ & $\begin{array}{l}32 \\
41 \\
13 \\
61 \\
59 \\
40 \\
48 \\
32 \\
35\end{array}$ & $\begin{array}{l}32 \\
41 \\
13 \\
61 \\
59 \\
46 \\
58 \\
47 \\
41\end{array}$ & $\begin{array}{l}\text { Ins. } \\
\text { Or. } \\
\text { Ins. } \\
\text { Or. } \\
\text { Ins. } \\
\text { Or. } \\
\text { Or. } \\
\text { Ins. } \\
\text { Ins. }\end{array}$ & $\begin{array}{l}\text { Ins. } \\
\text { Ins. } \\
\text { Ins. } \\
\text { Ins. } \rightarrow \text { Or. } \\
\text { Ins. } \\
\text { Ins. } \\
\text { Ins. } \rightarrow \text { Or. } \\
\text { Ins. } \\
\text { Ins. }\end{array}$ & $\begin{array}{l}\text { N/A } \\
14 \\
\text { N/A } \\
\text { N/A } \\
\text { N/A } \\
17 \\
8 \cdot 5 \\
15 \\
15\end{array}$ & $\begin{array}{l}7 \cdot 7 \\
7 \cdot 6 \\
5 \cdot 9 \\
7 \cdot 2 \\
7 \cdot 8 \\
9 \cdot 8 \\
8 \\
7 \cdot 5 \\
5\end{array}$ & $\begin{array}{l}16 \cdot 5 \\
15 \\
9 \cdot 6 \\
11 \\
11 \\
27 \\
11 \\
\overline{12} \cdot 6\end{array}$ & $\begin{array}{l}21 \\
21 \\
21 \cdot 6 \\
12 \\
16 \\
35 \\
\frac{12}{16 \cdot 5}\end{array}$ & $\begin{array}{l}0 \\
0 \\
0 \\
4 \\
3 \\
8 \\
7 \\
0 \\
1\end{array}$ & $\begin{array}{r}9 \\
8 \\
3 \\
5 \\
6 \\
10 \\
6 \\
4 \\
7\end{array}$ & $\begin{array}{r}9 \\
7 \\
2 \\
13 \\
\rightarrow \\
\rightarrow 17 \\
8 \\
\rightarrow\end{array}$ \\
\hline
\end{tabular}

Or. = oral therapy; Ins. Insulin; N/A = not availaole; $\mathrm{KCH}=$ King's College Hospital

$\rightarrow=$ persisting residual symptoms

an average of five years later (range 4-6 years in seven and 9 and 12 months in the remaining two). The patients were seen frequently over the intervening period and the time of cessation of major symptoms was taken from the records which were kept in considerable detail and with great regularity in all cases.

\section{CASE HISTORIES}

Illustrative case histories for the three patients in whom nerve biopsy was performed are given.

Case 1, a male aged 32 years, was diagnosed as diabetic in August 1976, although thirst, polyuria, lethargy and some weight loss had been evident for nine months prior to this. One month after beginning insulin treatment he complained of intermittent sharp stabbing pains and severe burning sensations affecting the soles of both feet. This was rapidly followed by intense contact discomfort affecting both legs and reaching as far as the thighs. It was continuous and likened to nettle stings. Provocative factors included cold weather and contact from clothes and bedclothes. Insomnia, impotence and depression ensued and by December 1975 his weight had fallen by $9 \mathrm{~kg}$ over the preceding 12 months. Some relief of foot symptoms was gained by applying hard massage.

On examination on admission to the Diabetic Department in December 1976 his weight was $58.8 \mathrm{~kg}$, approximately $17 \mathrm{~kg}$ below normal. The cranial nerves were normal. Bilateral proliferative retinopathy was present. There were no abnormal motor signs in the limbs, all the tendon reflexes were present and the plantar responses were flexor. On sensory testing light touch and pinprick sensation was impaired bilaterally below ankle level. The resting pulse rate was $112 / \mathrm{min}$ and regular and the blood pressure was $140 / 90 \mathrm{~mm} \mathrm{Hg}$ lying and $110 / 80$ standing. Heart rate variation with respiration measured 21 . The foot pulses were palpable.

Good control of the diabetes with insulin was obtained and his weight promptly rose. Within two months of admission, his severest symptoms had subsided. By May 1977 his impotence had lessened and șoreness was restricted to his feet. All symptoms except impotence had cleared by July 1978 and at the second full assessment, 4 years later, there had been no relapse. Neurological examination then was normal except for patchy loss for light touch affecting all the toes. Blood pressure was $120 / 80 \mathrm{~mm} \mathrm{Hg}$ lying and standing and the resting pulse rate was $68 / \mathrm{min}$. His heart rate variation with respiration measured 17 (normal), and the heart rate increased by 24 after standing for 15 seconds (normal). The Valsalva manoeuvre ratio was 1.73 (normal). Retinopathy had been stable since laser treatment in 1977 and there was no proteinuria.

Case 2, a male aged 41 years, was diagnosed as diabetic in January 1977 , following a short history of thirst, lethargy and weight loss. Treatment was begun with diet and chlorpropamide. In June 1977, severe shooting and burning pains developed, together with tingling paraesthesiae, initially in both feet, spreading up as far as the waist. These were worse at night. He also experienced aching and mild numbness in his fingers. Cutaneous contact discomfort was constant and only silk pyjamas were bearable. By November 1977, weight loss was accelerating, impotence had developed and he was sleeping poorly.

On examination on admission to the Diabetic Department in November 1977, his weight was $15 \mathrm{~kg}$ below normal. The cranial nerves were normal and there was no evidence of retinopathy. There were no abnormal motor signs in the limbs, his tendon reflexes were all obtainable and the plantar responses flexor. There was no detectable sensory loss for any modality, but light touch and pinprick over both legs elicited an unpleasant burning response.

Case 9, a male aged 41 years, was diagnosed as diabetic in 1972 and was managed on chlorpropamide for two years until insulin was begun in 1974. In June 1978, urgent admission to hospital with ketoacidosis followed several months of weight loss and general ill health. Just before discharge he complained of tingling in the toes bilaterally, sharp burning pains in both feet, and pains shooting into his legs. He had noticed no aggravating factors, and had not been aware of weakness or sensory loss. There had been no disturbance of sensation in the upper limbs or elsewhere. He was referred to King's College Hospital for further advice.

On examination on admission to the Diabetic Department he was generally wasted and had lost $6 \mathrm{~kg}$ in weight over the preceding 12 months. He had been impotent for 9 months. His cranial nerves were normal apart from background retinopathy. There were no abnormal motor signs in the limbs, his tendon reflexes were all present and the 
plantar responses flexor. There was no detectable sensory loss for any modality in the upper or lower limbs, or over the trunk. His resting pulse rate was $95 / \mathrm{min}$, his blood pressure was $105 / 70 \mathrm{~mm} \mathrm{Hg}$ with no postural drop, and all pulses were palpable. His heart rate variation with respiration measured 4 (grossly abnormal). The heart rate increased by 14 on standing (normal).

Good diabetic control was achieved with Actrapid and Insultard twice daily and the pain improved with analgesics and diazepam. However, he was readmitted within two months having lost a further $6 \mathrm{~kg}$ in weight and with increased severity of his symptoms. These included burning sensations in his feet "like standing on red hot sand", contact discomfort, insomnia, profound anxiety and depression. The findings on examination were unchanged. Diabetic control, which had lapsed, was re-established and within two weeks his symptoms had improved.

At a second full assessment four years later he still complained of burning feet at night, relieved by Palfium. The appreciation of light touch and temperature (hot and cold) was impaired over the distal half of both feet, but the tendon reflexes were obtainable and there were no abnormal motor signs. Heart rate variation with respiration was still abnormal at 7 , although the heart rate on standing rose by over 20 . Blood pressure was $110 / 70 \mathrm{~mm} \mathrm{Hg}$ with no postural drop and all pulses were present.

\section{NERVE CONDUCTION STUDIES}

Sensory and motor conduction were investigated in an upper and lower limb in seven patients. Bipolar surface electrodes were used to record sensory action potentials (sural, radial, median, ulnar), mixed nerve potentials (median, ulnar) and compound muscle potentials (abductor hallucis, extensor digitorum brevis, thenar, hypo thenar). Not all were studied in every patient. Attention was paid to amplitude, form and latency of the evoked potentials.

\section{NERVE BIOPSY}

Fascicular biopsies were obtained under local anaesthesia from the sural nerve posterior to the lateral malleolus. The specimens were fixed by immersion in cacodylate-buffered paraformaldehyde-glutaraldehyde fixative ${ }^{6}$ for $3 \mathrm{~h}$ at room temperature and postfixed in $1 \%$ cacodylate-buffered osmium tetroxide for a further $3 \mathrm{~h}$. After dehydration in graded concentrations of ethanol, one portion was embedded in Araldite with propylene oxide as an intermediary. Another portion of each specimen was used for teased fibre preparations. Single fibres were isolated in unpolymerised Araldite and mounted on glass slides in Araldite.

A morphometric assessment of myelinated fibre size and density was made on semithin sections stained with thionin and acridine orange and photographed at a final magnification of $\times 1400$. All fibres were counted. External fibre diameter was measured using a Sonic digitiser interfaced to a Commodore Pet computer. The lesser diameter was used for fibres with an elliptical outline. Fibres sectioned in the paranodal region or at Schmidt-Lanterman incisures were excluded. The density and mean diameter of unmyelinated axons was assessed in ultrathin sections stained with lead citrate and uranyl acetate and examined in a Philips
EM201 electron microscope. A systematic random sampling technique was employed and measurements made on photographs at a final magnification of $\times 10,000$. The proportion of denervated Schwann cell profiles (that is unassociated with axons) was also estimated.

\section{Results}

\section{Symptoms}

The symptom complex was very characteristic in this group of cases. The most obtrusive features were weight loss and persistent pain distally in the lower limbs. Tingling paraesthesiae were reported by some patients. Despite the considerable weight loss, there were no abnormalities of motor function.

Severe, constant, burning pain affecting mainly the soles of the feet was the most frequent description and was often likened to walking over unbearably hot sand. The feet would frequently feel swollen as if the shoes had suddenly become too small. Attempts at relief were made by removing shoes whenever possible, although the sensation of swelling was purely a subjective phenomenon. Worsening at night and at times of relaxation was almost invariable. The pain was maximal in the feet and distally in the legs, but often involved the whole of both lower limbs and, in two instances, the hands and lower trunk.

One of the worst symptoms was variously described as an intermittent sharp, searing, shooting or stabbing pain, usually originating under the toes and radiating to the heel or up the front of the leg as far as the knee. Those for whom it was a major problem likened it to an electric shock or stated that it felt like a razor slicing the skin. A sensation of bruising and persistent aching particularly affected the thighs and upper legs.

Contact discomfort, which was highly characteristic, was present in all the patients and was associated with intense hypersensitivity of the skin. It was often described as a sensation of stinging nettles or having the skin abraded with coarse sandpaper. This was provoked mainly by bed clothing and clothes, especially socks and trousers, and became an important factor in causing insomnia.

Weight loss (fig 1) was severe in all cases, on average $14.2 \mathrm{~kg}$ (range $9.5-27 \mathrm{~kg}$ ), amounting to a mean percentage loss of 19.4 (range $12-35 \%$ ). Pain in every instance began following a decrease in weight. The major symptoms coincided with the point of maximal loss and had substantially improved before normal weight was regained. One patient became so cachectic that he was considered elsewhere to have disseminated malignancy.

All of the patients became depressed and anorexic during the most severe symptoms. The phrase "life is hardly worth living" was frequently used. Time off 

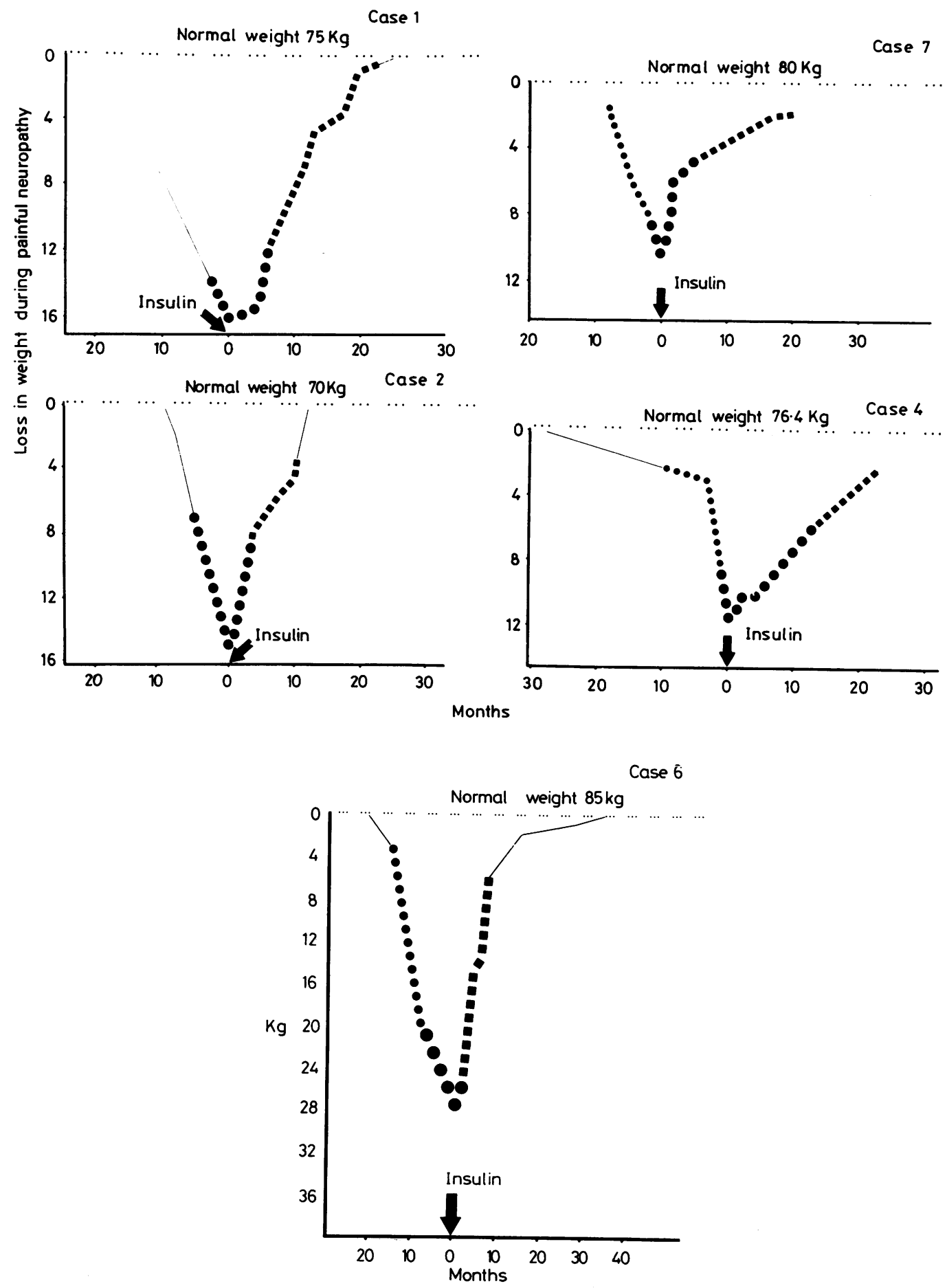

Fig 1 Weight change in fve cases of painful neuropathy. Documented weight loss without painful symptoms. (-) - moderate symptoms; severe symptoms; 1 residual symptoms. 
work was required by all and the adolescent boy's schooling suffered considerably.

Impotence was present in all the adult patients and, with one exception, has persisted.

All of the major features (except impotence) had ceased to be distressing within six months after the onset of severe symptoms in seven patients and in the remaining two by 10 months. Thereafter the symptoms decreased with clear endpoints in six. By the time of the second assessment, two had minor residual symptoms and one still complained of nocturnal burning affecting the feet. None had suffered a relapse.

\section{Neurological signs}

Sensory impairment or loss was in general slight and, when present, was less extensive than suggested by the distribution of the pain. It was, in the main, restricted to distal areas of the lower limbs. In some instances, as in Cases 1,2 and 9, there was no clinically detectable sensory loss, although quantitative sensory testing was not undertaken. Apart from sensory impairment, discomfort from tactile stimuli (allodynia) and overreaction to painful stimuli (hyperpathia), were often evident. In all but two instances, the signs of sensory neuropathy have improved (fig 2). The ankle jerks have either remained the same or improved (fig 3).

Extensive autonomic testing was not performed. Postural hypotension (a systolic fall of $33 \mathrm{~mm} \mathrm{Hg}$ or more) was initially present in four cases but had resolved by the second assessment. The heart rate variation with breathing (beat to beat) (table 2) was normal in two, borderline in two and definitely abnormal in four at the first assessment. At the second assessment, only six patients were retested: five showed no change and the sixth, who was not tested initially, showed a result that was possibly normal for his 67 years of age.

Vascular and renal status

There was no evidence of peripheral vascular dis-

Table 2 Heart rate variation during deep breathing at furst and second assessment.

\begin{tabular}{llll}
\hline Case & Age & 1st assessment & 2nd assessment \\
\hline 1 & 13 & 24 & 17 \\
2 & 32 & $21 \cdot 1$ & $23 \cdot 3$ \\
3 & 41 & $14 \cdot 9$ & - \\
4 & 32 & 12 & 11 \\
5 & 61 & - & - \\
6 & 48 & 8 & 9 \\
7 & 40 & 7 & 7 \\
8 & 41 & 4 & 5 \\
9 & 59 & 2 & \\
\hline
\end{tabular}

Normal $>12^{21}$

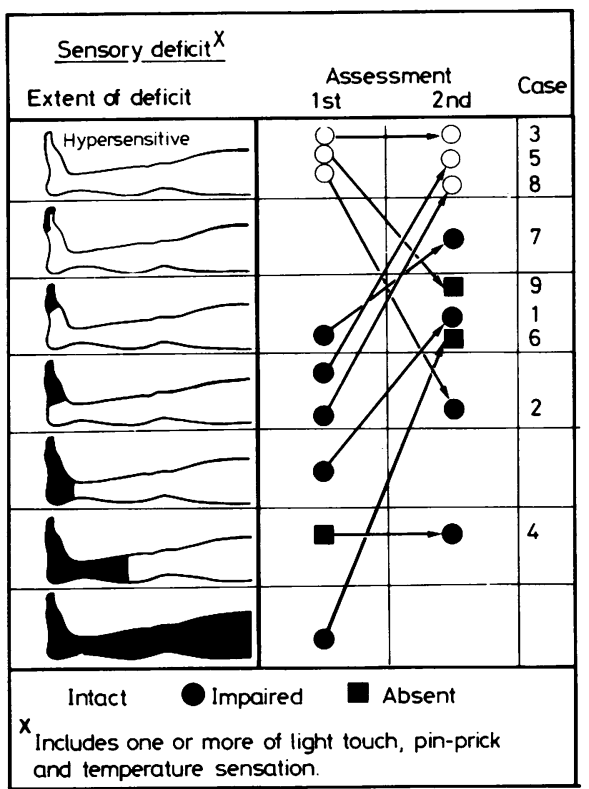

Fig 2 Extent of sensory deficit at first and second assessment. Shaded areas indicate extent of sensory impairment.

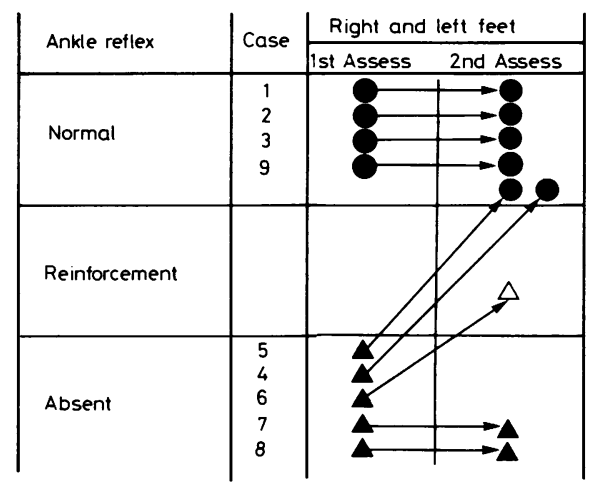

Fig 3 Ankle reflexes at frst and second assessment.

ease in any of the patients. At least one pulse was palpable in all the feet. Foot pulses remained unchanged at the second assessment. Six of the nine patients had no retinopathy at the time they experienced painful symptoms. Of the other three, two had proliferative changes and the other background changes. At the second assessment a further two had developed background retinopathy.

One of the patients with proliferative retinopathy had significant proteinuria, while none of the other eight had proteinuria at any time. 
Nerve conduction studies

In one patient, Case 3 , all results were well within the normal range. Sural potentials were absent in three cases $(2,5$ and 6$)$, but otherwise all patients had sensory and mixed nerve potentials with amplitudes at least $40 \%$ of the lowest value in $95 \%$ of normal subjects. A particularly sensitive index of generalised neuropathy, the ulnar mixed nerve potential, was never reduced by more than $30 \%$. Foot muscle potentials were of normal amplitude and latency in all patients except one. Hand muscle potentials were of normal amplitude in all except one, but distal motor latency to thenar muscles was slightly increased in three. Median nerve motor conduction velocity was just within normal limits in all except one patient, in whom it was $45 \mathrm{~m} / \mathrm{s}$.

\section{Nerve biopsy findings}

Sural nerve biopsies were performed in three cases (1, 2 and 9), but the specimen was unsuitable for morphometric studies in Case 1 . The vasa nervorum were normal in all three patients, no inflammatory infiltrates were observed and amyloid deposits were not detected.

Myelinated fibre density was reduced in Case 9 $\left(3,585 / \mathrm{mm}^{2}\right)$ and borderline in Case $2\left(4,344 / \mathrm{mm}^{2}\right)$. The mean fibre density for normal subjects is 7,000 $\pm 1,600 / \mathrm{mm}^{2} .{ }^{7}$ The size-frequency distributions for these two cases (fig 4) show a loss of the normal large fibre peak, but both large and small fibres were affected. In the normal subject, $29 \%$ of fibres have a diameter greater than $8 \mu \mathrm{m}:^{7}$ in Case 9 , this was $1 \%$ and in Case 2, 9.1\%. Mean fibre diameter was 5.47 $\mu \mathrm{m}$ in the former and $4.74 \mu \dot{\mathrm{m}}$ in the latter.

The density of unmyelinated axons was within normal limits in both cases, being $38,402 / \mathrm{mm}^{2}$ in Case 9 and $49,112 / \mathrm{mm}^{2}$ in Case 2. The normal range is $19,000-56,900 / \mathrm{mm}^{2} .^{8}$ However, mean diameter was reduced, being 0.48 and $0.47 \mu \mathrm{m}$ respectively. The normal mean is $1.13 \mu \mathrm{m}$, with a range of 0.99 $1.28 \mu \mathrm{m} .^{8}$

The number of Schwann cell profiles (subunits) was also assessed in electron micrographs, and the proportion unassociated with axons. The number of subunits was increased in both, the density being $98,514 / \mathrm{mm}^{2}$ in Case 9 and $99,093 / \mathrm{mm}^{2}$ in Case 2, as

Table 3 Frequency of abnormalities in isolated myelinated nerve fibres from sural nerve in Cases 1,2 and 9. Percentage frequency in parenthesis.

\begin{tabular}{llllll}
\hline Case & Normal & $\begin{array}{l}\text { Axonal } \\
\text { degeneration regeneration }\end{array}$ & $\begin{array}{c}\text { Axomalion } \\
\text { tion }\end{array}$ & Uncertain \\
\hline 1 & $52(59)$ & $20(23)$ & $4(4 \cdot 5)$ & $5(5 \cdot 5)$ & $7(8)$ \\
2 & $67(78)$ & $10(12)$ & $2(2)$ & $6(7)$ & $1(1)$ \\
9 & $58(67)$ & $14(16)$ & $8(9)$ & $6(7)$ & $1(1)$ \\
\hline
\end{tabular}

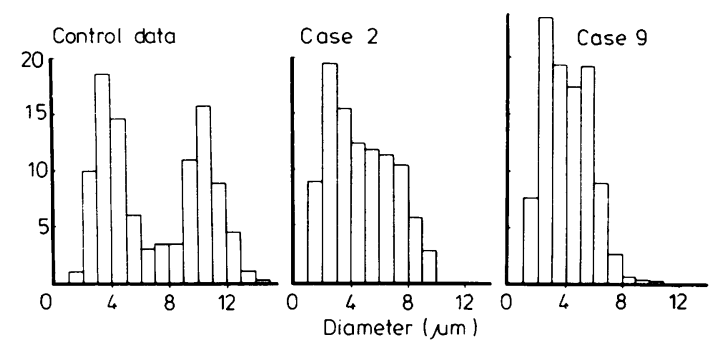

Fig 4 Sural nerve myelinated fibre size-frequency distribution. Biopsies performed at peak of painful symptoms in two insulin dependent diabetics compared with control data. ${ }^{23}$

was the proportion of denervated subunits, which was $33 \%$ and $31 \%$ respectively. In the normal, the average density is $25,600 / \mathrm{mm}^{2}$ with a range of $13,500-35,000 / \mathrm{mm}^{2}$ and a proportion of denervated subunits of $14 \% .^{8}$

Teased fibre preparations were examined in all three cases. The results are shown in table 3 . All three showed an excess of abnormal fibres. The predominant abnormality was evidence of recent axonal degeneration (fibres with linear rows of myelin ovoids) together with fibres that had undergone axonal regeneration. No active demyelination was seen but some segmental remyelination was evident. The fibres that were classified as showing abnormalities of uncertain nature represented those in which several internodes of normal appearances were accompanied by one or more short thinly myelinated internodes at one end. In this circumstance, it was not possible to state whether this indicates axonal regeneration after focal axonal degeneration or segmental remyelination.

\section{Management}

Improved control of diabetes with insulin was associated with weight gain and thereafter a diminution in the severity of symptoms (fig. 1 and table 1 ).

No medication consistently relieved symptoms. Relief of insomnia was one of the most important facets of treatment, leading to improvement in well being. Relief of cutaneous contact discomfort could be achieved by wearing loose clothing (or none), and by the use of a cradle to elevate bedclothes. Shoes were discarded whenever possible. Firm massage to the feet relieved the symptoms of burning in two patients, whereas three others found relief by soaking their feet in cold water.

\section{Discussion}

Painful neuropathy is one of the most unpleasant complications of diabetes and considerable uncer- 
tainty surrounds its cause and evolution. Such neuropathic symptoms may develop in either insulin dependent or noninsulin dependent individuals, irrespective of the duration of their diabetes and in whom diabetic control is not always very poor. In our cases, the onset of symptoms was always associated with, and indeed preceded by, precipitous weight loss which was sometimes catastrophic. Several lost more than $10 \mathrm{~kg}$ and one $27 \mathrm{~kg}$. The loss can at times be so severe that carcinomatosis is suspected. Weight gain always preceded the resolution of the neuropathic symptoms and restoration to normal weight was the rule.

It is of some interest that all the cases were male, although the size of the sample is relatively small. This apparent sex predisposition is reminiscent of the predominance of males in uraemic neuropathy. ${ }^{9}$

The sensory changes in our cases were surprisingly slight in relation to the magnitude of the pain, but cutaneous hyperaesthesia with hyperpathia and allodynia was at times prominent. One case had no sensory loss; presumably the number of degenerating fibres was insufficient to reach the proportion necessary for this to be clinically detectable. More precise quantitative studies ${ }^{10}$ might have revealed abnormalities in cutaneous sensory thresholds. No abnormal motor signs were demonstrable, but tendon reflex depression was seen, although the ankle jerks were still present in four of our cases. The abnormalities demonstrated in the nerve conduction studies were of the kind and degree found in patients with mild or asymptomatic neuropathy, except in one instance where no abnormality was detected. Other reports have commented on the poor correlation between electrophysiological measurements and the severity of symptoms. ${ }^{11}$

There is a striking lack of correlation with other complications of diabetes. Six patients had no evidence of retinopathy at first assessment, and only one of the three patients with retinopathy also had evidence of nephropathy. This suggests that acute painful neuropathy is not due to microvascular disease. This is in keeping with the current view that symmetrical peripheral neuropathy is secondary to metabolic disturbance ${ }^{12}$ although it is clear that at times symmetrical distal neuropathy may result from the summation of multifocal proximal lesions..$^{13}$ The vasa nervorum were normal in the biopsy specimens from our three cases.

The nerve biopsy findings indicate a relatively acute process causing axonal degeneration. The peripheral distribution of the sensory changes suggests that this is length related. ${ }^{14}$ Myelinated fibres of all sizes were affected. The relative preservation of the small fibre peak in the histograms may be due to the presence of regenerating axons. Although the myelinated fibre size density in Case 2 was borderline, the existence of a considerable excess of denervated Schwann cell profiles indicates fibre loss. The denervated Schwann cells were both of the type related to degeneration of myelinated fibres (Büngner bands) and of myelinated axons. ${ }^{15}$ The presence of denervated Schwann cells is a highly sensitive indicator of fibre degeneration. ${ }^{8}$ The density of unmyelinated axons was within normal limits for the two biopsies, but axonal degeneration was confirmed by the reduction in mean axon diameter in both. This could indicate selective loss of the larger axons or an admixture of small regenerating unmyelinated sprouts (or both). The preservation of fibre density suggests that the latter explanation is the more important. Some segmental demyelination and remyelination were present, but this was not a prominent change. Axonal degeneration and segmental demyelination may be independent effects of the diabetic process. ${ }^{16}$

The rate and completeness of clinical recovery in some instances suggest that the axonal degeneration may at times be very distal. This could explain the relatively modest abnormalities in the nerve conduction studies and their complete normality in one case. In future patients it will be important to study digital sensory action potentials from the toes.

Brown $e^{a} l^{3}$ described the nerve biopsy findings in two cases of painful diabetic neuropathy and found a predominant loss of small myelinated fibres and presented evidence that also indicated involvement of unmyelinated axons. These changes correlated with a predominant loss of pain and temperature sensation with sparing of the sensory modalities carried by large myelinated fibres. This therefore does not accord with the present observations in which selective pain and temperature sensory loss was not evident and in which the biopsy findings were of loss of fibres of all sizes. Behse et al $^{16}$ also found loss of fibres of all diameters in their cases of diabetic neuropathy associated with pain.

Said et al. ${ }^{17}$ have recently reported a series of five patients with progressive small fibre type diabetic neuropathy that produced a pseudosyringomyelic dissociation of sensory loss together with severe autonomic disturbances. Spontaneous pains were a feature in three and plantar ulcers and neurogenic arthropathy in three. Nerve biopsies indicated a distal axonal degeneration that initially affected unmyelinated and small fibres on a length related basis. There was some associated demyelination. Such cases of progressive small fibre neuropathy with pain are clearly different from the acute reversible cases that we have described. This again emphasises the plurality of syndromes that may occur as manifestations of diabetic neuropathy. 
Our teased fibre studies, which showed active fibre degeneration, are of interest in the light of those obtained by Dyck et al. ${ }^{18}$ These authors, in observations on 72 cases of peripheral neuropathy, found that pain was more commonly associated with active fibre breakdown than with other types of pathological change. The significance of this is uncertain, but it raises the possibility that the pain may arise from regenerating axonal sprouts. ${ }^{19}$ Another factor that has to be considered is the question of secondary abnormalities of CNS function at spinal level. Loh and Nathan ${ }^{20}$ concluded that this is indicated for peripheral nerve lesions when tactile stimuli cause pain and when pain and cutaneous hypersensitivity extend beyond the original territory of the lesion. Thus the proximal spread of pain in the legs and even onto the trunk in some of our cases, in the absence of sensory loss in this distribution, could imply abnormal excitability of dorsal horn neurons rather than lesions of the peripheral axons proximally in the limbs or over the trunk.

Treatment is always difficult. It must be underpinned by gaining the confidence of the sufferer. Advice that the severe pain will always remit comes as a great relief. This one fact is often remembered long afterwards by the patient. Improvement is associated with meticulous diabetic control using insulin either by a twice daily injection with blood glucose monitor control, or as a constant subcutaneous infusion. The benefit of insulin infusion in this context has been reported..$^{22}$ Drugs given for symptomatic relief such as sedatives, simple analgesics, phenytoin, carbamazepine and Motival (fluphenazine and nortryptiline) are sometimes but not always of value. Percutaneous electrical stimulation to the area of the pain may occasionally produce benefit, but its effect is not dramatic.

Acute painful diabetic neuropathy is a distinct entity. It is always extremely unpleasant, but the most severe symptoms always remit, with negligible residual clinical manifestations. Relapses have not been observed. It remains uncertain whether it is a prelude to the usual form of diabetic sensory polyneuropathy. However, conspicuous sensory loss has not developed subsequently and neither foot ulcers nor sepsis were encountered in any of our patients even after five to six years.

We thank Dr DA Pyke for his helpful advice and encouragement. AGA is supported by a research grants from Allen and Hanburys. Financial support from the National Fund for Research into Crippling Diseases is also gratefully acknowledged.

\section{References}

' Pryce TD. On diabetic neuritis, with a clinical and pathological description of three cases of diabetic pseudo-tabes. Brain 1893;16:416-24.

${ }^{2}$ Leyden E. Die Entzündung der Peripheren Nerven (1888). Cited by Pryce TD. Brain 1893;16:416-24.

${ }^{3}$ Brown MJ, Martin JR, Asbury AK. Painful diabetic neuropathy: a morphometric study. Arch Neurol 1978;33:164-71.

${ }^{4}$ Pavy FW. Address on diabetes, Washington International Congress, 1887. Med News (Philadelphia) 1887; Sept 23, 357.

${ }^{5}$ Ellenberg M. Diabetic neuropathic cachexia. Diabetes 1974;23:418-23.

${ }^{6}$ Karnovsky MJ. A formaldehyde-glutaraldehyde fixative of high osmolality for use in electron microscopy. $J$ Cell Biol 1965;27:137A.

${ }^{7}$ Behse F, Buchthal F, Carlsen F, Knappeis GG. Hereditary neuropathy with liability to pressure palsies. Electrophysiological and histopathological aspects. Brain 1972;95:777-94.

${ }^{8}$ Behse F, Buchthal F, Carlsen F, Knappeis GG. Unmyelinated fibres and Schwann cells of sural nerve in neuropathy. Brain 1975;98:493-510.

${ }^{9}$ Nielsen VK. The peripheral nerve function in chronic renal failure: a survey. Acta Med Scand (suppl) 1974;573:1-32.

${ }^{10}$ Dyck PJ, O'Brien PC, Bushek W, Oviatt KF, Schilling $\mathrm{K}$, Stevens JC. Clinical vs quantitative evaluation of cutaneous sensation. Arch Neurol 1976;33:651-5.

"Greene DA, Brown MJ, Braumstein SS, Schwartz SS, Asbury AK, Winegrad I. Comparison of clinical course and sequential electrophysiological tests in diabetes with symptomatic polyneuropathy and its implications for clinical trials. Diabetes 1981;30:139-47.

${ }^{12}$ Thomas PK. The aetiological problems of diabetic neuropathy. In: Goto Y, Horiuchi A and Kogure K ed. Diabetic neuropathy. Amsterdam: Excerpta medica, 1982:3-10.

${ }^{13}$ Sugimura K, Dyck PJ. Multifocal fiber loss in proximal sciatic nerve in symmetric distal diabetic neuropathy. $J$ Neurol Sci 1982;53:501-9.

${ }^{14}$ Sabin TD, Geschwind N, Waxman SG. Patterns of clinical deficits in peripheral nerve disease. In: Waxman SG ed. Physiology and Pathobiology of Axons. New York: Raven Press, 1978:431-38.

${ }^{15}$ Ochoa J, Mair WGP. The normal sural nerve in man. II Changes in the axons and Schwann cells due to ageing. Acta Neuropathol (Berl) 1969;13:217-39.

${ }^{16}$ Behse F, Buchthal F, Carlsen F. Nerve biopsy and conduction studies in diabetic neuropathy. $J$ Neurol Neurosurg Psychiatry 1977;40:1072-82.

${ }^{17}$ Said G, Slama S, Selva J. Progressive centripetal degeneration of axons in small fibre type diabetic polyneuropathy. A clinical and pathological study. Brain, in press.

${ }^{18}$ Dyck PJ, Lambert EH, O'Brien PC. Pain in peripheral neuropathy related to rate and kind of fiber degeneration. Neurology (Minneap) 1976;26:466-71.

19 Thomas PK. Pain in peripheral neuropathy: clinical and 
morphological aspects. In: Ochoa $\mathbf{J}$ and Culp W ed. Abnormal Nerves and Muscles as Impulse Generators. 1982:553-67.

${ }^{20}$ Loh L, Nathan PW. Painful peripheral states and sympathetic blocks. J Neurol Neurosurg Psychiatry 1978;41:664-71.

${ }^{21}$ Mackay JD, Page M McB, Cambridge J, Watkins PJ. Diabetic autonomic neuropathy-the diagnostic value of heart rate monitoring. Diabetologia 1980;18: 471-8.

${ }^{22}$ Boulton AJM, Drury J, Clarke B, Ward JD. Continuous subcutaneous infusion in the management of painful diabetic neuropathy. Diabetes Care 1982;5:386-91.

${ }^{23}$ O'Sullivan DJ, Swallow M. The fibre size and content of the radial and sural nerves. J Neurol Neurosurg Psychiatry 1968;31:464-70. 